\title{
Perancangan Komplek Pusat Pendidikan dan Pelatihan Sepakbola di Kabupaten Gresik dengan Tema Tropis Modern
}

\author{
Sahrul Fahmi Bahtiar', Annisa Nur Ramadhani², Amir Mukmin Rachim ${ }^{3}$ \\ 1,2,3Jurusan Arsitektur, Fakultas Teknik Sipil dan Perencanaan, Institut Teknologi Adhi Tama Surabaya, \\ Surabaya, Indonesia \\ Email: ${ }^{1}$ sahrulfahmi10@gmail.com, ${ }^{2}$ annisanur@itats.ac.id
}

\begin{abstract}
Football belongs to one of popular sports recently. Some areas in Indonesia have developed football players from the early ages by establishing football academy and training centres. Like other big cities in Indonesia, Gresik has potential in developing football. The results of survey demonstrated that people have tremendous enthusiasm in this sport and thus, they require more complete facilities for football training. The design of football training and education centre in Gresik is expected to be able to provide facilities such as places for training, education, coaching, and research concerning football. The expression of building that can accommodate educational facilities can be used by football players to increase their capacities and expertise in playing football so that their achievement can be improved, particularly for Gresik people who are interested in football. This final assignment aimed at understanding the implementation of modern tropical architecture theme including the design of land order, shape, space, and other elements for designing a football training and education centre in Gresik Regency. It can adapt with the recent conditions of climate and environment as well as modern design to provide complete facilities so that all imaginations regarding football training and development specifically in Gresik Regency and Indonesia can be actualized.
\end{abstract}

Keywords: training and education, football, modern tropic

\begin{abstract}
Abstrak. Sepakbola merupakan salah satu olahraga yang paling popular pada saat ini. Beberapa wilayah di Indonesia membentuk pemain-pemain sepakbola dimulai dari usia dini, dengan mendirikan akademi sepakbola dan juga pusat-pusat pelatihan sepakbola. Gresik, seperti halnya beberapa kota besar lainnya di Indonesia juga memiliki potensi besar dalam perkembangan sepakbola. Berdasarkan survei yang dilakukan dapat dikatakan bahwa masyarakatnya banyak yang memiliki antusiasme luar biasa pada olahraga ini, sehingga perlu adanya fasilitas latihan sepakbola yang menyediakan sarana lebih lengkap. Pada penerapan pusat pendidikan dan pelatihan sepakbola yang dirancang di Kabupaten Gresik ini diharapkan mampu menyediakan fasilitas yaitu tempat pelatihan, pendidikan, pembinaan, dan penelitian tentang sepakbola sehingga dapat menunjang ekspresi bangunan yang mewadahi adanya sarana-sarana pendidikan agar dapat digunakan oleh para pemain sepakbola untuk meningkatkan kemampuan dan keahlian bermain sepakbola sehingga mampu meningkatkan prestasi khususnya masyarakat di Kabupaten Gresik dalam bidang sepakbola. Artikel ini dimaksudkan untuk memahami tentang penerapan tema Arsitektur Tropis Modern yang mencakup tatanan lahan, bentuk, ruang dan elemen lainnya pada perancangan pusat pendidikan dan pelatihan sepakbola di Kabupaten Gresik yang dapat beradaptasi dengan kondisi iklim, lingkungan serta desain modern masa kini untuk menyediakan sarana dan fasilitas lengkap sehingga dapat mengakomodasi semua angan-angan mengenai pembinaan dan pengembangan sepakbola khususnya di kabupeten Gresik dan Indonesia.
\end{abstract}

Kata Kunci: pendidikan dan pelatihan, sepakbola, tropis modern

\section{Pendahuluan}

Sepakbola adalah olahraga yang paling popular dan paling banyak digemari olah masyarakat, mulai dari anak-anak remaja hingga orang dewasa. Gresik, seperti halnya beberapa kota besar lainnya di Indonesia yang memiliki potensi sangat besar dalam perkembangan sepakbola. Di sisi lain, ironisnya segala potensi ini tidak diiringi dengan kemudahan-kemudahan dalam mengakses fasilitas yang berkaitan dengan sepakbola. Dari survey yang telah dilakukan di Gresik terdapat juga beberapa lokasi pelatihan sepakbola (SSB) yang tersebar akan tetapi belum ada satu yang menjadi pusat orientasi dan referensi yang bisa menyatukan visi, sekaligus menjadi barometer pengembangan sepakbola untuk masyarakat Gresik serta belum adanya wacana dari pemerintah tentang penyediaan bangunan sebagai 
fasilitas-fasilitas yang lebih lengkap bagi pendidikan dan pelatihan sepakbola di Kabupaten Gresik. Tabel 1 berikut menunjukkan jumlah Klub dan sekolah sepakbola yang ada di kabupaten Gresik.

Tabel 1. Data Klub Anggota dan SSB di Kabupaten Gresik

\begin{tabular}{|c|c|c|c|c|}
\hline No & Kelas Utama & Kelas I & Kelas II & $S S B$ \\
\hline 1 & Pjbgres & Putra Regas & Dharma Bakti Fc & Petrogres \\
\hline 2 & Sidayu Putra & Menganti Fc & Cerme Fc & Pjb Gres \\
\hline 3 & Persik Kembangan & Sidayu Fc & Pandawa Fc & Semen Indonesia \\
\hline 4 & Ps. Semen Gresik & Sekapuk Fc & Pumagress Fc & Akademi Wcp \\
\hline 5 & Persada Delegan & Evolution & Obor Muda Fc & G2 Manyar \\
\hline 6 & Dukun Putra & Ps. Rajawali Putra & Putra Mandiri Fc & Pasopati-Cerme \\
\hline 7 & Balong Panggang Pr & Psdm Mangare & Palapa Fc & Persada Delegan \\
\hline 8 & Ps. Petrogres & Cerme Putra & Roked & Sumurber \\
\hline 9 & Persim Manyar & Perseta Metatu & Benjeng Fc & Sekapuk Fc \\
\hline 10 & Legowo Fc & Ppfc Prambangan & Popos Fc & Ssb Pelangi \\
\hline 11 & Bintang 9 Benjeng & Porasda Kedanyang & Poas Muda Fc & Cahaya Muda \\
\hline 12 & Driyorejo Fc & Ps. Popel Lumpur & Bima Amora & Bima Amora \\
\hline 13 & Psp Poncangan & Asg Giri & Akademi Wcp & Serdadu \\
\hline 14 & Te Ha Er Pojok & Duduk Sampeyan Fc & Persegat Fc & Putra Bina Bola \\
\hline 15 & & Bungah $\mathrm{Fc}$ & Ps. Putra Buana & Indonesia Raya \\
\hline 16 & & & Kuda Sembarni Fc & Elang Sakti \\
\hline 17 & & & Psgs & Tsa-Driyorejo \\
\hline 18 & & & Menganti United & Putra Setia \\
\hline 19 & & & & Putra Mandiri \\
\hline 20 & & & & Putra Kidang \\
\hline 21 & & & & Roked Fc \\
\hline 22 & & & & Persiked's \\
\hline 23 & & & & Setya Bhakti \\
\hline 24 & & & & Akrap Muda Fc \\
\hline 25 & & & & Persiputra \\
\hline 26 & & & & Jurit Fc \\
\hline 27 & & & & Sss Joko Tingkir \\
\hline 28 & & & & Putra Raharha Fc \\
\hline 29 & & & & Ssb Bina Bola Muda \\
\hline
\end{tabular}

Dari pemikiran yang diidukung oleh data tersebut, disusunlah sebuah konsep perencanaan lengkap dengan ide-ide gagasan. Hal tersebut menjadi dasar dalam mendesain suatu Pusat Pelatihan Sepakbola yang dilegkapi sarana pelengkap berupa lapangan latihan, gedung tempat belajar latihan, asrama serta fasilitas penunjang lainnya. Perencanaan ini memiliki penekanan pada Arsitektur Tropis Modern untuk menanggapi karakter lingkungan Kabupaten Gresik Perancangan Komplek Pusat Pendidikan dan Pelatihan Sepakbola di Kabupaten Gresik dengan Tema Tropis Moder diharapkan mampu mengakomodasikan semua angan-angan mengenai pembinaan dan pengembangan sepakbola khususnya di Gresik dan Indonesia pada umumnya.

Arsitektur merupakan kegiatan menyusun suatu tautan yang mempersatukan ruang, bentuk, kiat, dan fungsi (Ching, 1979). Arsitektur adalah upaya manusia dalam merespon lingkungan, salah satunya adalah iklim. Arsitektur tropis adalah suatu karya arsitektur yang mampu mengantisipasi problematik yang ditimbulkan iklim tropis. Arsitektur modern adalah suatu istilah yang diberikan kepada sejumlah bangunan dengan gaya karakteristik yang mengutamakan kesederhanaan bentuk dan menghapus segala macam ornamen. Karakter ini disinyalir pertama muncul pada sekitar tahun 1900. Pada tahun 1940 gaya ini telah diperkuat dan dikenali dengan Gaya Internasional dan menjadi bangunan yang dominan untuk beberapa dekade dalam abad ke-20 ini. (Nareswarananindya et al., 2021)(Ramadhani Nur \& Faqih, 2019)(Pembinaan et al., 2020)

Dalam penerapannya karakteristik bangunan Tropis Modern yaitu: (1) Memiliki bentuk dan ruang yang mampu beradaptasi dengan kondisi iklim dan lingkungan. (2) Memiliki bentuk atap yang miring untuk mengalirkan air agar lebih teratur dan mencegah radiasi panas manahari. (3) Memiliki struktur dinding yang kokoh. (4) Memiliki jumlah jendela yang cukup banyak sebagai pengatur cahaya 
alami. (5) Menggunakan warna cerah dan material bernuansa local. (6) Memiliki area terbuka hijau (Aditya Nugraha Jurusan Arsitektur, 2019).

Perancangan pusat pendidikan dan pelatihan sepakbola dikota Gresik adalah suatu area yang mewadahi kegiatan pendidikan, pembelajaran, pelatihan pembinaan tentang olahraga sepakbola yang dilaksanakan dalam kurun waktu tertentu yang bertujuan untuk meningkatkan keterampilan dalam bermain sepakbola meliputi teori maupun praktek yang didukung dengan adanya fasilitas-fasilitas yang mewadahi sehingga mampu meningkatkan prestasi khususnya masyarakat di kota Gresik.

Dalam mendukung adanya ketersediaan fasilitas maka bangunan pusat pendidikan dan pelatihan sepakbola harus didukung dengan adanya bangunan modern yang dapat mendukung semua kegiatan yang ada. Didalam bangunan itu nantinya akan mewadahi beberapa fungsi yang harus dipenuhi, misalnya: ruang teori / belajar, lapangan pertandingan, asrama, ruang pers, fitness, swimming pool, ruang-ruang penunjang lainnya, adanya ruang tersebut dapat menjadi satu keterkaitan antara ruang yang satu dengan ruang yang lain makadariitu sebuah bangunan pendidikan dan pelatihan harus dapat menfasilitasi semua kebutuhan yang ada sehingga kegiatan yang ada didalamnya juga ikut terorganisir dengan baik.

\section{Metode Penelitian}

Metode penelitian untuk desain ini menggunakan metode deskriptif kualitatif dengan menganalisis, menggambarkan, dan meringkas kondisi dari berbagai data-data yang dikumpulkan. Datadata tersebut dikumpulkan menggunakan: (1) Teknik Observasi yaitu dengan pengamatan langsung di lapangan. Adapun metode yang digunakan dalam mengumpulkan data langsung di lapangan yaitu dengan (a) Wawancara. (b) Dokumentasi. (c) Metode Literatur. (2) Studi Pustaka yaitu mengumpulan data yang dilakukan dengan mempelajari buku-buku referensi, laporan-laporan, majalah-majalah, jurnal-jurnal dan media lainnya yang berkaitan dengan obyek penelitian (Ramadhani et al., 2019). Berikut adalah gambar diagram metodologi penelitian.

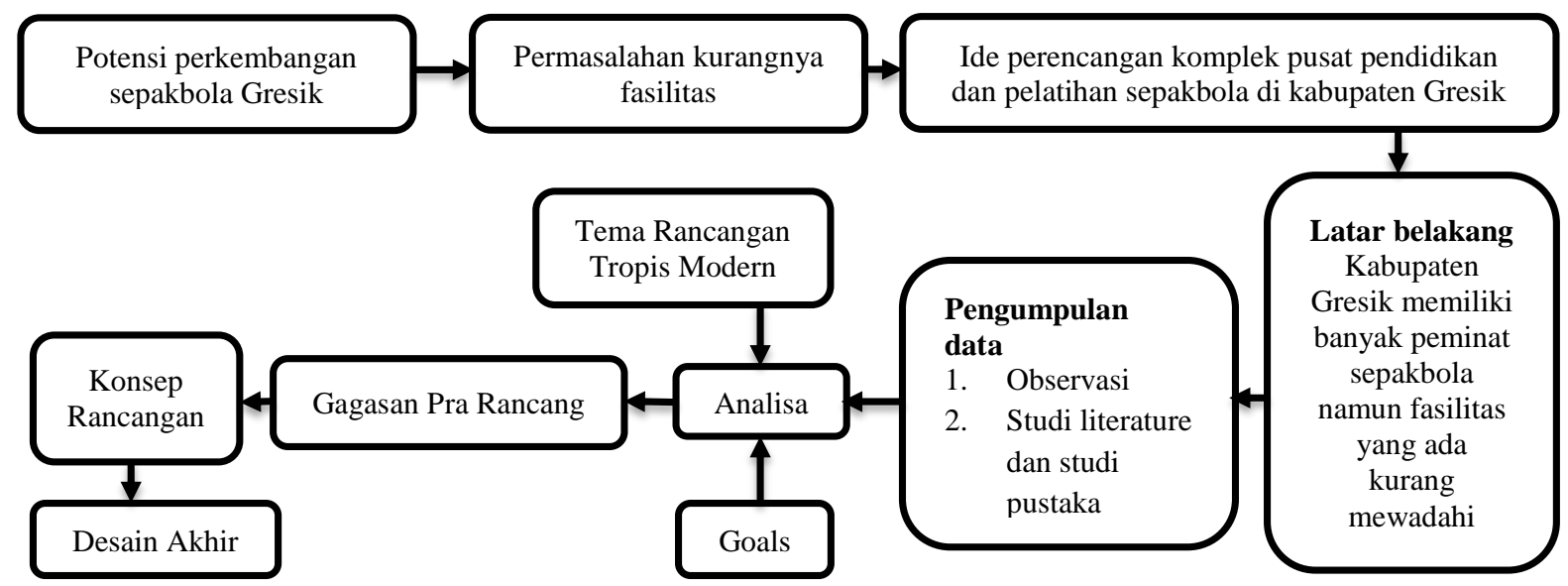

Gambar 1. Diagram Metode Penelitian

\section{Pembahasan}

\subsection{Studi Lapangan Gedung Pelatihan Sepakbola Persegres}

Merupakan sebuah tempat yang digunakan sebagai pelatihan sepakbola ataupun tempat dalam menggelar pertandingan. Fasilitas yang ada pada bangunan ini adalah Lapangan sepakbola, GOR serbaguna, Joging track, Area Kebugaran dan lain-lain. 


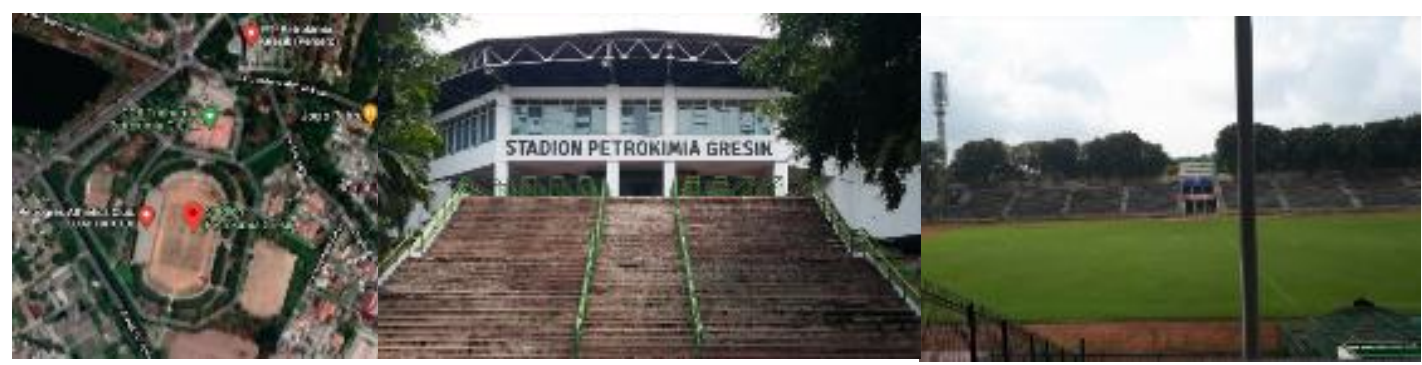

Gambar 2. Pelatihan Sepakbola Persegres (kiri) Site Plane; (tengah) Tampak Depan; (kanan) Lapangan

Kajian arsitektur yang terkandung dalam pelatihan sepakbola Persegres: (1) Tatanan lahan menggunakan pola Radial. (2) Bentuk Bangunan perwujudan dari arsitektur Tropis dengan penggunaan atap miring dan terlihat oversteak, jendela yang cukup lebar. (3) Ruangan memiliki material yang bernuansa alami. (4) Struktur material bangunan kebanyakan menggunakan beton, baja dan kayu.

\subsection{Studi Literatur Gedung Pelatihan Sepakbola Manchester City}

Fasilitas yang ada pada bangunan ini adalah Lapangan sepakbola untuk latihan, lapangan sepakbola untuk bertanding, ruang belajar pendidikan, lapangan Indoor, Kantor, Area Kebugaran, kolam renang, spa, dan lain-lain.

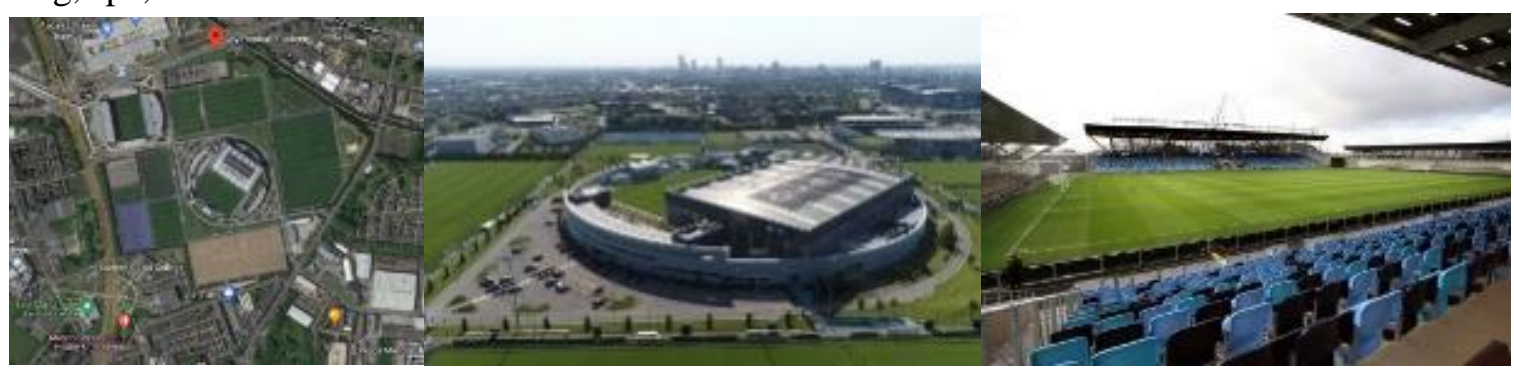

Gambar 3. Pelatihan sepakbola Manchester City (kiri) Site Plane; (tengah) Tampak Mata Burung; (kanan) Lapangan

Berikut adalah kajian arsitektur yang terkandung dalam pelatihan sepakbola Manchester City: (a) Tatanan lahan menggunakan pola Radial. (b) Bentuk bangunan perwujudan dari arsitektur Modern dengan bentuk sederhana yaitu lingkaran tanpa adanya furniture yang berlebihan. (c) Ruangan memiliki material yang bernuansa alami. (d) Struktur material bangunan kebanyakan menggunakan beton, baja dan kayu.

\subsection{Program Ruang dan Analisa Tapak}

(1) Program Ruang (a) Fasilitas Penerima meliputi drop off, lobi, resebsionis, ruang tunggu, parkir pengelola, parkir siswa, parkir pengunjung. (b) Fasilitas utama meliputi lapangan besar, lapangan kecil, tribun, ruang ganti pemain, ruang ganti wasit, area staf pelatih, area belajar pendidikan, asrama. (c) Fasilitas pengelola. (d) Fasilitas penunjang meliputi area kesehatan, Area kebugaran, café, restorant, musholla. (e) Fasilitas servis. (f) Fasilitas keamanan.

(2) Analisa tapak (a) Lokasi tapak yang digunakan dalam perancangan ini tepatnya di jalan raya Banjarsari, kecamatan Cerme, kabupaten Gresik, Jawa Timur. Memiliki luasan sekitar 3.5 hektar. (b) Berdasarkan analisa potensi lebih dikedepankan pada tampilan view, baik dengan adanya view to site ataupun view from site. (c) Berdasarkan analisa kebisingan, memberikan redaman suara dengan adanya vegetasi ataupun menjauhkan fasilitas ruang yang memerlukan ketenanangan cukup tinggi. (d) Berdasarkan analisa Zonifikasi maka disimpulkan bahwa adanya berbagai lingkup area yang telah ada akan dibagi berdasarkan zonifikisi yang bersifat umum (Publik, Transisi, dan Privat). Pada analisa ini ME akan diletakan dibagian jalan sisi timur laut karena memiliki akses jalan luar yang lebih lebar sedangkan SE diletakan dibagian tenggara untuk mempermudah akses menuju sisi jalan yang lainnya. (e) Dari Analisa klimatolo sesuai adanya tema Tropis Modern yaitu memaksimalkan adanya cahaya matahari alami maka pada bagian timur site akan difungsikan sebagai fasilitas olahraga dan pelatihan 
lapangan dikarenakan cahaya matahari pada pagi hari akan memberikan manfaat lebih terhadap kesehatan tubuh.

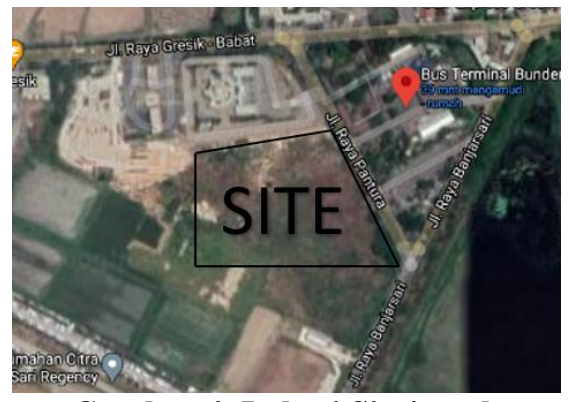

Gambar 4. Lokasi Site/tapak

\section{Perancangan Konseptual}

Pada tahap perumusan rancangan konseptual, akan membahas perihal terkait program dan konsep dalam merancang Komplek Pusat Pendidikan dan Pelatihan Sepakbola di Kabupaten Gresik dengan Tema Tropis Modern.

\subsection{Program Rancangan}

Program rancangan pada desain bangunan yang dirancang ini menggunakan tahapan dengan mengacu pada rangkaian tahapan program perancangan (lihat Gambar 5):

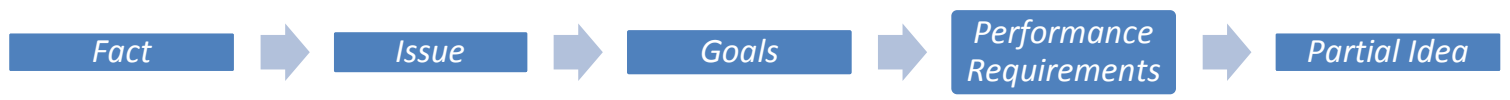

\section{Gambar 5. Program Rancangan}

Fakta mengacu pada keadaan sebenarnya kondisi fasilitas sepakbola di kabupaten Gresik yang kurang lengkap. Hal ini memunculkan sebuah issue dalam perkembangannya yaitu pernyataan kualitas desain, pelayanan fasilitas, perhatian, topik, keadaan yang membutuhkan jawaban perancangan (design response) dari permasalahan tersebut untuk diselesaikan. Setelah itu diterapkanlah sebuah tujuan pernyataan akhir yaitu goals. Goals merupakan pernyataan yang menggerakkan tindakan untuk memberikan beberapa paparan tujuan yang nantinya menjadi akhir dari hasil perancangan komplek pusat pendidikan dan pelatihan sepakbola di kabupaten Gresik yang dipadukan dengan adanya performance requirements yaitu sebagai masukan guna mengadakan perbaikan untuk peningkatan, sehingga dari hasil program rancangan tersebut terciptalah sebuah partial idea yaitu sebuah hasil ide dasar yang diimplementasikan sebagai perwujudan komplek pusat pendidikan dan pelatihan sepakbola pada rancangan selanjutnya yang lebih baik.

\subsection{Konsep Rancangan}

Tema arsitektur tropis modern yang merupakan gaya arsitektur yang menggabungkan kenyamanan iklim, lingkungan dan alam dengan desain masa kini serta penyesuaian kehidupan masyarakat modern. Konsep sportif, adalah suatu konsep bangunan yang dirancang dengan desain yang jujur, seimbang, komunikatif tepat sesuai dengan kegunaannya tanpa mengabaikan keunggulan/langgam dari lingkungan sekitarnya. Sehingga konsep sportif tepat untuk diterapkan sebagai konsep makro dalam Perancangan Komplek Pusat Pendidikan dan Pelatihan Sepakbola di Kabupaten Gresik dengan Tema Tropis Modern.

Konsep Mikro. (a) Tatanan lahan efektif, merupakan suatu konsep tatanan lahan yang didesain secara efektif mempermudah akses ataupun zonifikasi didalam lingkungan site terhadap aktifitas yang ada. (b) Bentuk modern, merupakan konsep bentuk desain bangunan dengan gaya karakteristik yang mengutamakan kesederhanaan dan desain masa kini. (c) Ruang adaptif, adalah suatu sifat yang dapat digunakan oleh sebuah ruang agar mampu beradaptasi dan menyesuaikan diri terhadap berbagai macam kondisi lingkungan sekitar. 


\section{Hasil Rancangan}

\subsection{Tatanan Lahan}

Pada tatanan lahan ini diambil dari bentuk pola yang ada di permukaan bola, sehingga bentuk lahan terlihat cukup lebar dan efektif untuk digunakan sebagai tempat fasilitas olahraga yang memiliki ruang terbuka cukup luas, dengan hal ini maka pola sirkulasi tatanan lahan yang diterapkan juga sama seperti bola yaitu menggunakan pola radial. Penerapan arsitektur tropis modern yang diterapkan pada lahan ini yaitu ditandai dengan adanya vegetasi-vegetasi yang cukup banyak di dalam area site, penggunaan warna terang pada bangunan site dan tersedianya beberapa ruang terbuka hijau. Gambar berikut menunjukkan tampak prespektif dari tatanan lahan komplek pusat pendidikan dan pelatihan sepakbola di kabupaten Gresik.

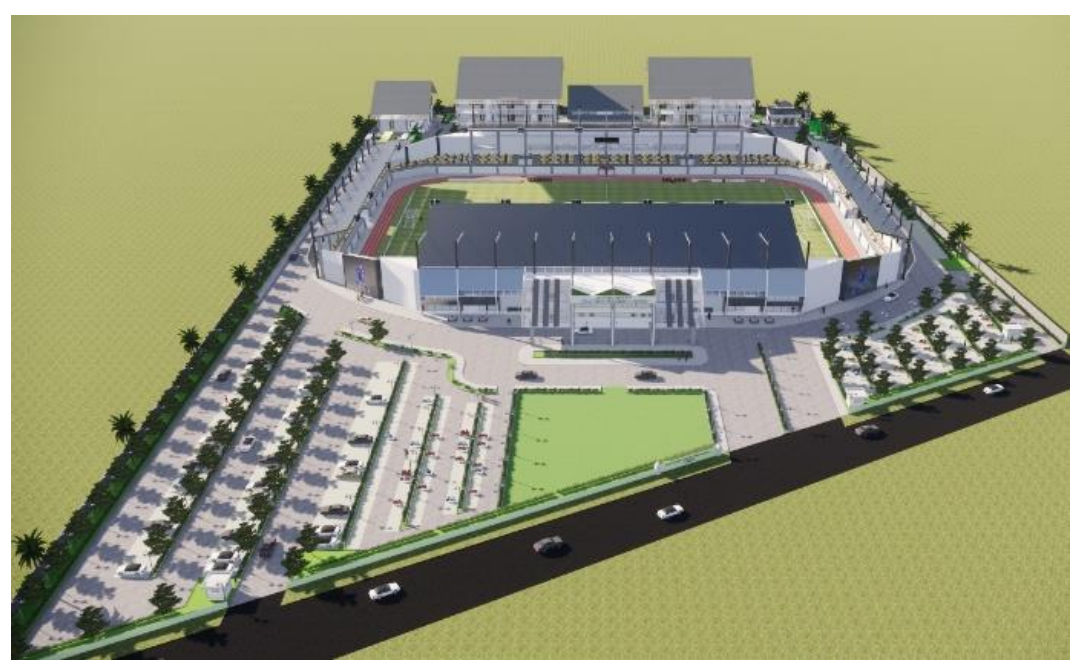

Gambar 6. Tatanan lahan perspektif

\subsection{Bentuk bangunan}

Bentuk bangunan utama stadion pada rancangan ini diambil dari pola gambar pada bola dengan bentuk segi enam, sedangkan bentuk bangunan penunjang disesuaikan dengan bentuk sirkulasi tatanan lahan. Pengembangan bentuk bangunan tersebut kemudian dilakukan dengan memunculkan bentuk 3D dari site dan pemotongan bentuk yang disesuaikan dengan kebutuhan ruang serta konsep modern dimana memiliki bentuk desain yang sederhana. Hasil pengembangan tranformasi bentuk tersebut kemudian dipadukan dengan tema tropis modern yang diterapkan seperti adanya bentuk atap yang miring, terdapat area penghijauan, material menggunakan bahan yang modern, terdapat bukaan ruang dan jendela yang cukup lebar sebagai penghawaan dan pencahaan alami didalam site. Gambar berikut menunjukkan bentuk-bentuk bangunan yang ada didalam komplek pusat pendidikan dan pelatihan sepakbola di kabupaten Gresik.

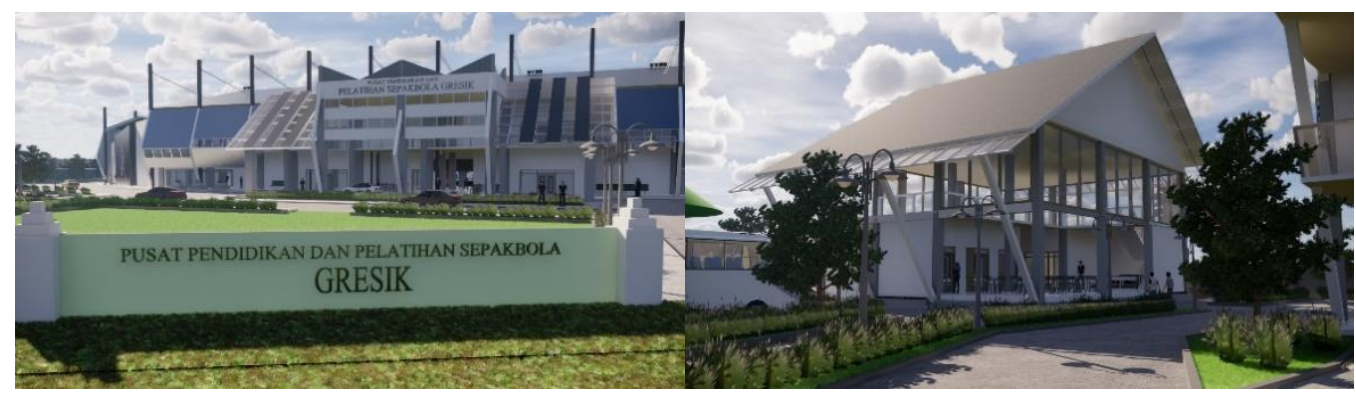

Gambar 7. Bentuk Bangunan (kiri) Stadion pelatihan; (kanan) Café dan restoran 


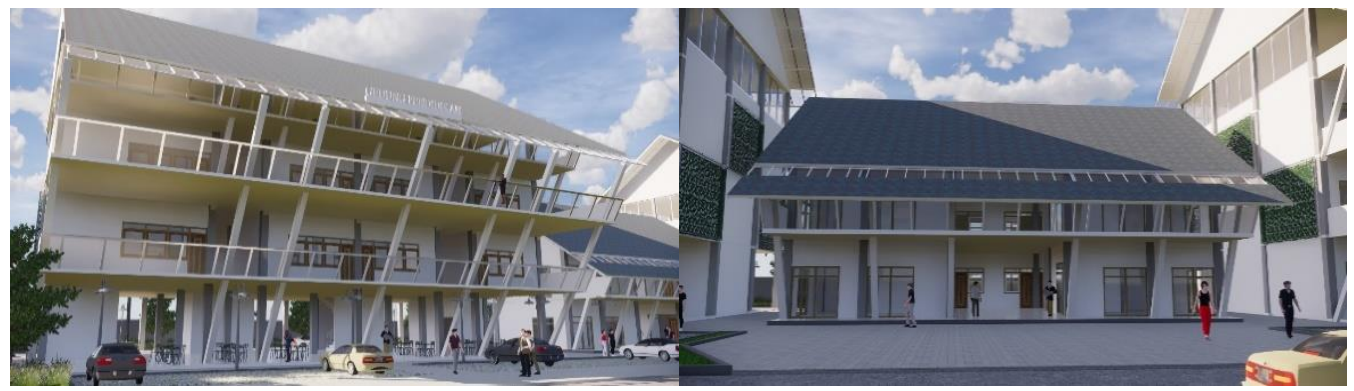

Gambar 8. Bentuk Bangunan (kiri) Gedung Pendidikan; (kanan) Gedung Kantor

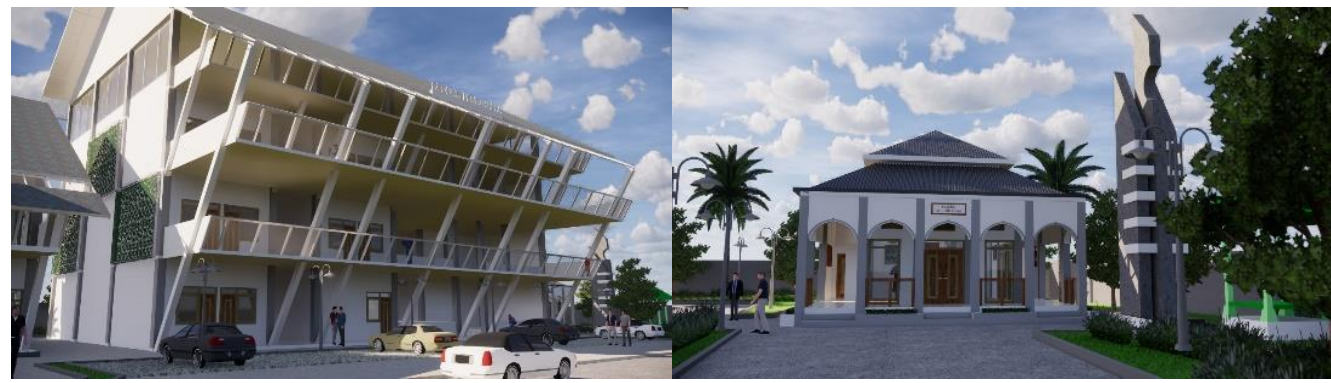

Gambar 9. Bentuk Bangunan (kiri) Gedung Penginapan; (kanan) Masjid

\subsection{Ruang}

Pada area ruangan ini lebih ditekankan terhadap adanya kegunaan ruang yang sesuai dengan fungsinya, sehingga penentuan jenis ruang tersebut dapat ditinjau dari klasifikasi area seperti ruang pelatihan di lapangan, ruang pendidikan belajar, dan ruang pendukung lainnya. Penerapan ruangan ini juga lebih ditekankan terhadap adanya konsep adaptif dari tema tropis modern yaitu beradaptasi dengan kondisi iklim dan lingkungan sekitar, hal ini diterapkan dengan adanya desain bukaan jendela pencahayaan dan penghawaan alami yang cukup banyak, adanya beberapa vegetasi yang ada di dalam ruangan serta penggunaan material interior yang terkesan modern dan bernuansa lokal. Gambar berikut menunjukkan tampilan ruang yang ada didalam komplek pusat pendidikan dan pelatihan sepakbola dikabupaten Gresik.

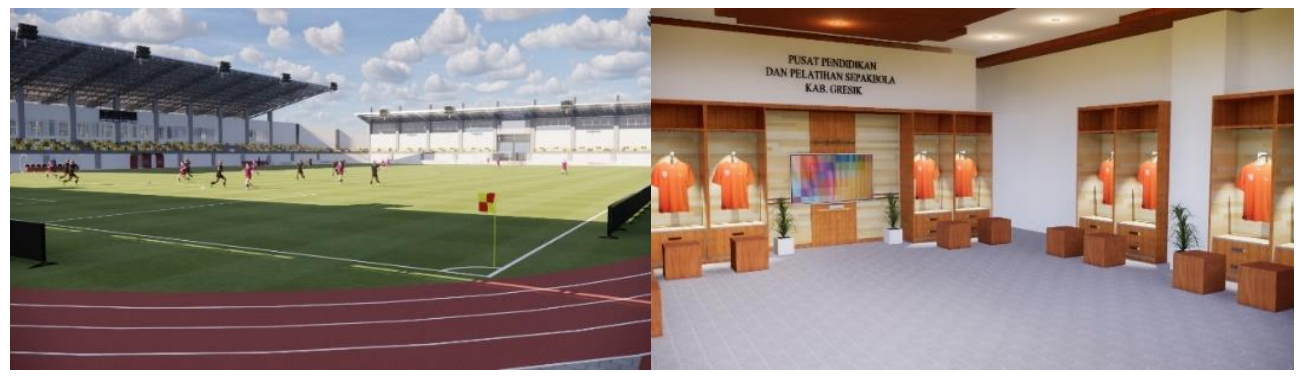

Gambar 10. Ruang (kiri) Lapangan Sepakbola; (kanan) Ruang Ganti Pemain

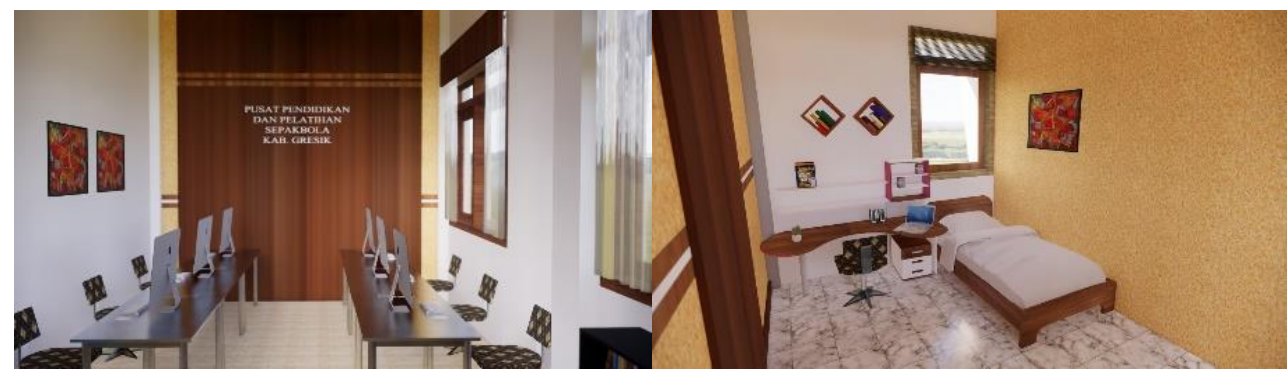

Gambar 11. Ruang (kiri) Kantor Pengelola; (kanan) Ruang Tidur Penginapan 


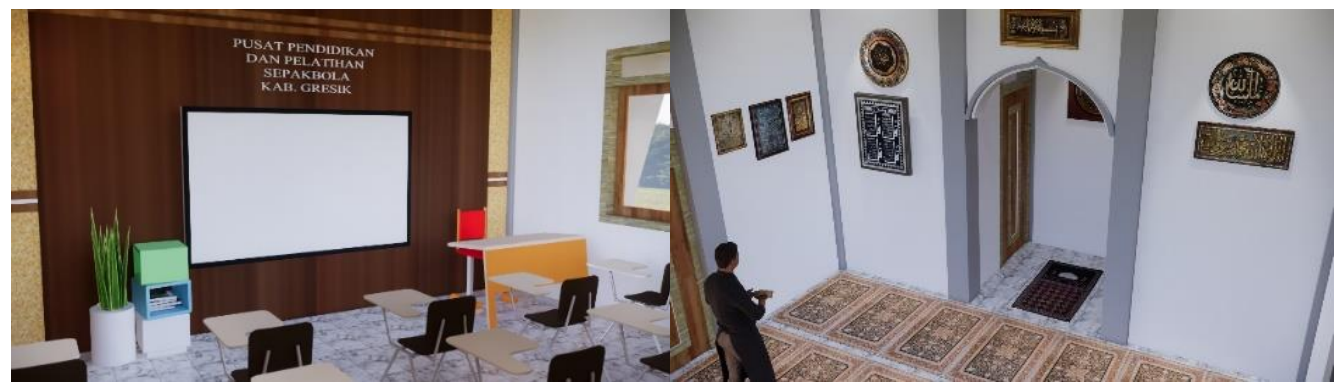

Gambar 12. Ruang (kiri) Kelas Teori; (kanan) Ruang Utama Masjid

\section{Kesimpulan}

Tujuan dari perancangan ini untuk menyelesaikan permasalahan yang timbul diakibatkan oleh kurangnya fasilitas yang mewadahi. Sehingga disusunlah sebuah konsep perancangan tersebut dengan tema yang sudah diterapkan yaitu tropis modern. Penggunaan tema ini memiliki potensi mampu beradaptasi sesuai dengan kondisi iklim dan lingkungan yang ada di wilayah kabupaten Gresik. Bentuk bangunan pada rancangan ini juga cukup unik dengan desain sederhana dan konsep modern yang dipadukan dengan bentuk damar kurung pada bangunan utama yaitu stadion pelatihan sebagai cirikhas dari kerajinan kabupaten Gresik sehingga mampu memberikan daya tarik lebih untuk menarik masyarakat agar banyak yang berkunjung ke dalam fasilitas tersebut. Dari adanya perancangan dan desain tersebut maka diharapkan mampu menciptakan sarana yang lebih lengkap untuk meningkatkan kemampuan dalam keahlian bermain sepakbola agar bisa meningkatkan prestasi khususnya masyarakat di kabupaten Gresik dalam bidang sepakbola.

\section{Referensi}

Aditya Nugraha Jurusan Arsitektur, R. (2019). Penerapan Tema Arsitektur Tropis Modern Terhadap Bangunan Stasiun Kereta Api Kota Bandung. Repository Tugas Akhir Arsitektur Itenas, 4(9), 110.

Ching, F. D. K. (1979). Arsitektur: Bentuk - Ruang dan. Erlangga.

Nareswarananindya, Laksono, S. H., Ramadhani, A. N., Budianto, A., Komara, I., \& Syafiarti, A. I. D. (2021). The design concept of bamboo in micro housing as a sustainable self-building material. IOP Conference Series: Materials Science and Engineering, $1010(1)$. https://doi.org/10.1088/1757-899X/1010/1/012026

Pembinaan, D. A. N., Muda, P., \& Di, P. (2020). Penerapan tema arsitektur modern tropis pada desain pusat pelatihan dan pembinaan pemain muda persebaya di surabaya. Seminar Teknologi Kebumian Dan Kelautan (Semitan II) Institut Teknologi Adhi Tama Surabaya (Itats) Indonesia, 2(ISSN), 645-648.

Ramadhani, A. N., Hayati, A., \& Faqih, M. (2019). The Effect of Physical Quality Improvement to Inhabitant's Sense of Place. EMARA: Indonesian Journal of Architecture, 5(1), 32-40. https://doi.org/10.29080/eija.v5i1.656

Ramadhani Nur, A., \& Faqih, M. (2019). Pendekatan Vernakular Kontemporer dalam Desain Pasar Wisata Apung Surabaya di Area Mangrove Wonorejo. Architecture, 5(2), 71-74. 